\title{
Tränenperlen weinen
}

Beatrice Pfister

Korrespondenz: Beatrice Pfister Elternforum www.dasanderekind.ch Schwalbenstrasse 10 CH-9200 Gossau

beatrice.pfister[at]bluewin.ch www.dasanderekind.ch
Manchmal hat man ja das Gefühl, dass die Pflegekräfte, die unsere Kinder zu Hause oder im Spital begleiten, sich nicht wirklich einfühlen können oder es auch nicht möchten - zumindest manche eine Art Schutzwall um sich tragen, der abgeklärt, ohne Gefühlsregung pflegen lässt.

Die berührenden Gedanken von Debora Zappel sprechen eine andere, einfühlsame Sprache, eine, der es gelingt, Unaussprechliches in Worte zu fassen, ein Kindergesicht so zu beschreiben, dass man es wahrlich vor sich sieht, mit dem Ausdruck in den Augen, als sei es da.

Debora Zappel nimmt die Leser auf ganz sachte Weise mit zu ihren Schützlingen, schwerkranken Kindern und Jugendlichen, die sie zu Hause pflegt.

Zum zwei Jahre alten Marco, der an einem seltenen, bösartigen Krebs leidet, Marco, der schon fast an seinem Lebensende angelangt ist, der Gefühle aus der Seele lesen kann und einen ganz speziellen Trost zu geben weiss.

Zur drei Monate alten Kim, die mit Trisomie 21 lebt und an einem schweren Herzfehler leidet, der nichts Gutes verheisst. Doch wenn Kim lacht, fallen alle Ängste und Zweifel ab.

Zum dreizehn Jahre alten Adis, der, schwer zerebral gelähmt, jeden Tag einen Sieg erringt im Steuern seines E-Rollis.

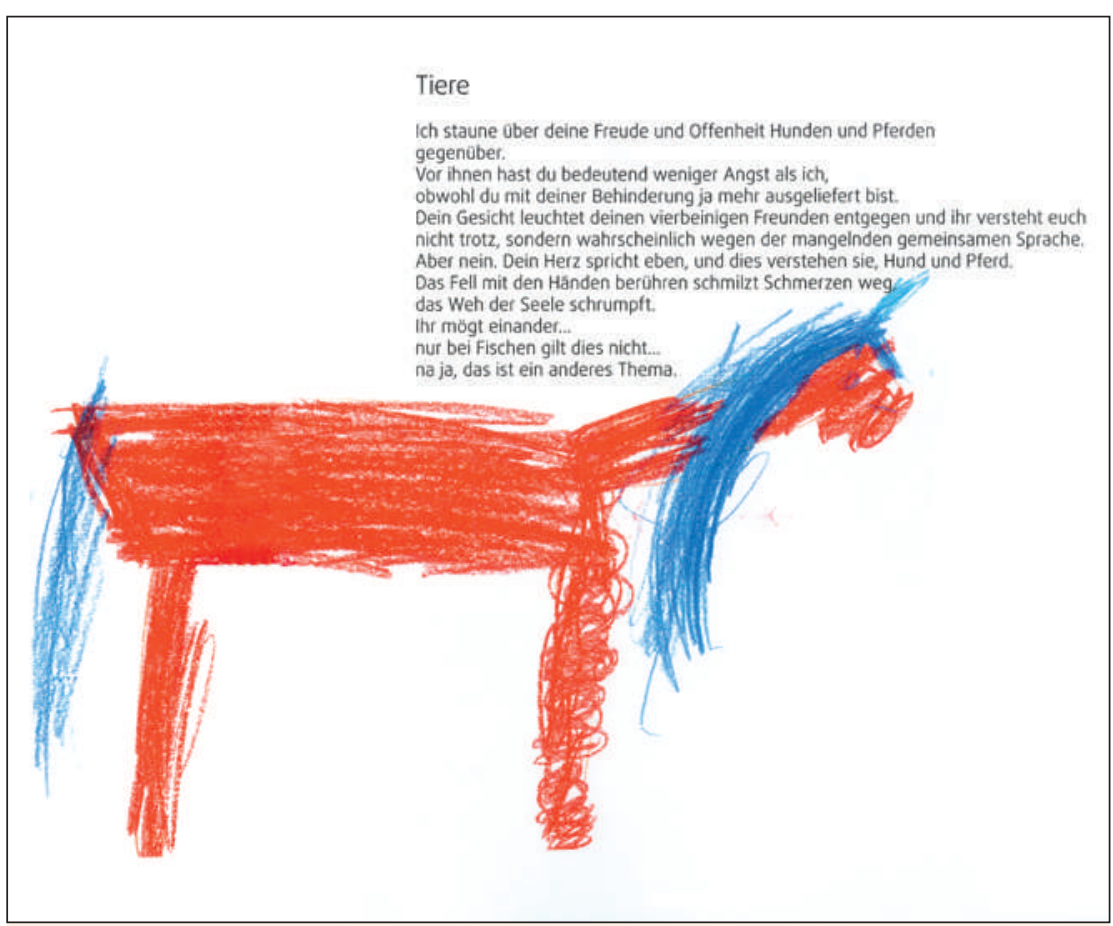

Gedanken zu Stephanie, 14 Jahre alt, die seit zwei Jahren an Mitochondrie leidet.

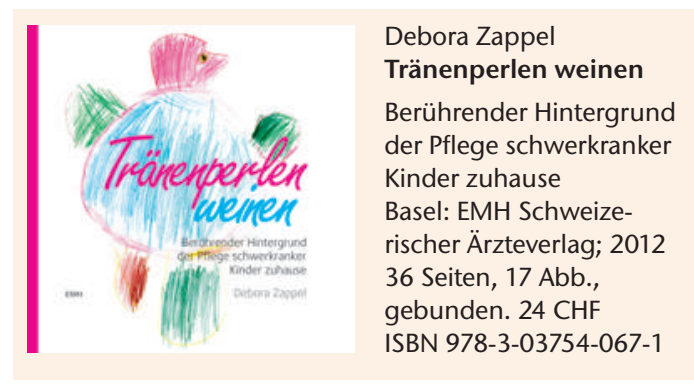

Zur zwei Jahre alten Amira, die an Cystischer Fibrose erkrankt ist, ein schmächtiges Kind und doch stark.

Zur fünfjährigen Anne, einem Kind mit schwerer Epilepsie, und deren Schwester Lena, die, so klein sie ist, unendlich viel Lebenshilfe für Anne leistet.

Zur elfmonatigen Benaja, die wegen einer Lippen-Kiefer-Gaumen-Spalte eine Dauersonde trägt, die allen Prognosen trotzt und doch noch fröhlich ist.

Zur zwei Jahre alten Ena mit angeborener Arthritis, einem Kind, dem sie alle sieben Tage eine schmerzhafte Spritze geben muss, die hilft gegen die Schmerzen - welch ein Widerspruch.

Zur kleinen Jasmin, die einjährig an Spinaler Muskelatrophie starb, die Augen wie ein Engel hatte.

Zum vier Jahre alten Jonathan, der schwer geistig und körperlich behindert ist, der sich selber haut, sich zu wehren scheint gegen etwas Unsichtbares, nur in sich Fühlbares.

Zur neunzehn Jahre alten Nadja, die mit einer fortschreitenden Muskelkrankheit lebt, die die Welt bereist, auf ganz eigene Weise.

Zur siebzehn Jahre alten Noemi, die wegen Mikrozephalie mehrfach behindert und den ganzen Tag auf Hilfe angewiesen ist und deren stilles Glück ein Gegenstand aus der Küche ist, mit dem sie sich stundenlang zu beschäftigen weiss.

Zur vierzehn Jahre alten Stephanie, die im Alter von zwölf an Mitochondriopathie erkrankt ist, die einen unvergleichlichen Charme hat.

Die Begegnungen mit diesen besonderen Kindern schildert sie mit Worten, von denen jedes einzelne wie Prosa wirkt. Feinfühlig, liebevoll, offen.

Hauchzart und doch eindringlich entführen die niedergeschriebenen Worte die Leser in ungeahnte Welten. Welten, von Kindern, von denen viele selber nicht mehr sprechen, die sich aber erfühlen lassen. Er hat mich sehr berührt, dieser kleine Band voller Gefühl, voller wesentlicher Gefühle, die eigentlich erst das Leben reich machen. 